\title{
Coupled-column liquid chromatography method with photochemically induced derivatization for the direct determination of benzoylureas in vegetables
}

María Dolores Gil García*, Dolores Barranco Martínez, María Martínez Galera, Piedad Parrilla Vázquez

Department of Analytical Chemistry, University of Almería, La Cañada de San Urbano, 04120 Almería, Spain

\begin{abstract}
The coupled-column (LC-LC) system, consisting of a first column packed with internal surface reversed phase (ISRP) (50x4.6 mm ID) and a Chrompack C18 (100x4.6 mm ID) as second column, allowed the simultaneous determination of five benzoylurea insecticides in dichloromethane $\left(\mathrm{CH}_{2} \mathrm{Cl}_{2}\right)$ extracts of vegetable samples without any clean-up step. This system was combined with a photochemically induced fluorescence (PIF) post-column derivatization in order to provide strongly fluorescent photoproducts from the non-fluorescent benzoylureas. Limits of detection ranged from 0.21 to $0.98 \mu \mathrm{g} \mathrm{L}^{-1}$ of pesticide (equivalent to $0.14-0.65 \mu \mathrm{g} \mathrm{kg}^{-1}$ in vegetable samples) and limits of determination ranged from 4.0 to $10.0 \mu \mathrm{g} \mathrm{L}^{-1}$ (equivalent to $2.7-6.7 \mu \mathrm{g} \mathrm{kg}^{-1}$ ). Linearity of the method was established between 2 and $1800 \mu \mathrm{g} \mathrm{L}^{-1}$, depending upon the compound. Validation of the total method was performed by randomly analyzing recoveries of four vegetable samples (aubergine, cucumber, green bean, and tomato) spiked at two levels of concentration (10.0 and $33.3 \mu \mathrm{g} \mathrm{kg}^{-1}$ ). The combination of the LC-LC system with PIF detection provides a sensitive, selective, and rapid method for the determination of pesticides in vegetable samples at levels lower than the maximum residue levels (MRLs) established for these compounds by Spanish legislation.
\end{abstract}

Keywords: Benzoylurea insecticides; Photochemically induced fluorescence; LC-LC separation; Vegetables

*Corresponding author: María Dolores Gil García (e-mail: mdgil@ual.es) 


\section{Introduction}

Liquid chromatography (LC) is a suitable technique for the determination of polar analytes [1]. Its wide application range, long-term stability, ease of use, low cost, and improved selectivity, using various detection systems, means that LC is widely used in pesticide residue analysis. In complex samples, such as vegetables, LC analysis is usually complicated by a large excess of polar interferents, making the determination of the most polar analytes, which appear in the first part of the chromatogram, difficult or impossible. In many cases these polar interferents can be largely removed by low-resolution clean-up such as off-line solid phase extraction (SPE). However, this additional step may lead to the partial loss of some compounds, as well as an increase of labor, time, and cost [2]. In addition, matrix compounds with retention times longer than those of the analytes do not really interfere, but cause an unfavorable increase in the time of analysis.

Multidimensional LC is a powerful tool for the analysis of high complexity samples, solving the above mentioned problems. The coupling of chromatographic columns with different separation mechanisms can be attractive in terms of selectivity, allowing the determination of some specific groups of pesticides. Sorbents with different retention mechanisms have been successfully applied to improve selectivity in SPE-LC [3-5].

The first column (C-1) must provide sufficient separation to remove the greater part of the numerous early eluting matrix interferences prior to elution of the first analyte. However, unnecessarily high separation power and dimensions must be avoided in this column as these features are inversely proportional to analyte sensitivity and also increase the reconditioning time of the column between analyses. Restricted access media (RAM) C-1 perform as desired, because they allow no retention of large molecules and no high resolution of analytes. The advantages of RAM columns with various types of materials were demonstrated in the determination of pesticides in serum [6, 7], soils [8, 9], and water [10]. In these studies, analytical columns packed with semipermeable surface (SPS) and internal-surface reversed-phase (ISRP) were tested as C-1. Generally, the ISRP column was the most favorable.

As for the analytical column (C-2), it suffices to select a column with a separation power higher than $\mathrm{C}-1$ with the aim of achieving the separation and analysis of pesticides, especially in the determination of polar compounds with poor retention.

Another advantage of LC-LC systems is that they allow the large-volume injection (LVI) of sample without causing extensive band broadening, which increases the sensitivity of the technique and makes it suitable for trace analysis in environmental samples. 
For the reasons given, the LC-LC technique is being used more and more for pesticide quantification with different detectors. The UV detector has been used in most of the applications $[9,11]$. However, UV detection cannot always provide sufficient sensitivity and/or selectivity and there are some studies using LC-LC systems in combination with selective detection methods, such as fluorescence (FD) [12] and mass spectrometry (MS) [13, 14].

Benzoylurea insecticides [15] are used in fruit and vegetables because of their ability to act as insect growth regulators [16]. Their properties, such as narrow spectrum of action, low acute toxicity to mammals, and high biological activity, make them suitable for inclusion in integrated pest management programs for crops [15]. On the other hand, interest in the safety of food products has increased, and pesticide residues in food crops have been the subject of increasingly strict regulations [17].

Benzoylurea residues are generally analyzed by LC using UV [18-21], FD [22], or MS detection [23-25]. Because of their high polarity and poor detectability using any kind of detector, these methodologies require considerable effort in sample preparation steps such as extraction, concentration, and clean-up techniques.

In a previous study [22], we developed a new methodology with LC linked to photochemically induced fluorescence (PIF) with post-column derivatization to determine benzoylurea insecticides in vegetable samples. The photodegradation mechanism certainly involves a modification of the aromatic moiety but is probably complex and therefore further investigation is necessary to characterize the structure of the photoproduct(s). However, from an analytical point of view, it is not really necessary to identify the structure of the fluorescent compound(s) formed (assuming reproducibility) [26]. Detection limits compared favorably with those obtained by LC-DAD and they are in the same order as those obtained by LC using MS detection and lower than the MRLs established in Spanish legislation. Despite the high sensitivity of the proposed method, an off-line SPE clean-up step was required to avoid coelution of polar matrix interferences.

The aim of this work was to develop an efficient LC-LCPIF-FD methodology to determine benzoylurea insecticides in vegetable samples, making unnecessary the clean-up step. This method consists of a simple solvent extraction of vegetable sample with dichloromethane and the instrumental processing of un-cleaned extracts by LC-LC with PIF post-column derivatization and fluorescence detection. These tandem techniques greatly increased specificity of analysis, as demonstrated by the selected compounds. 


\section{Experimental}

\subsection{Chemicals and solvents}

Analytical standards (pestanal quality) of triflumuron (TFM), flufenoxuron (FF), diflubenzuron (DFB), lufenuron (LF) and hexaflumuron (HFM) were obtained from Riedelde Haën (Seelze, Germany).

Analytical reagent grade solvents, methanol $(\mathrm{MeOH})$ and acetonitrile $(\mathrm{ACN})$, were obtained from Merck (Darmstadt, Germany). Dichloromethane and anhydrous sodium sulphate of pesticide residue analysis quality were obtained from Panreac (Barcelona, Spain).

LC-grade water was obtained by purifying demineralized water in a Milli-Q system (Millipore, Bedford, MA, USA). Mobile phases were filtered through a $0.45 \mu \mathrm{m}$ cellulose acetate (water) or Teflon (methanol) filters and degassed with helium prior and during use. All standard solutions and samples were filtered through Millipore membrane Teflon filters $(0.45 \mathrm{~lm}$ particle size $)$ before injection into the chromatographic column.

\subsection{Instrumentation}

The system consists of an isocratic Model 510 LC pump (P-1) and gradient Model 600 LC pump (P-2) from Waters (Milford, MA, USA), a Rheodyne six-port injection valve (Model 7725) with a $500 \mu \mathrm{L}$ sample loop, a Type 7000 high-pressure column-switching valve (V) from Rheodyne (Berkeley, CA, USA), and a Model 474 variable-wavelength scanning fluorescence detector (D) from Waters.

A 50x4.6 mm ID column packed with $5 \mu \mathrm{m}$ Pinkerton ISRP GFII-S5-80 (Regis) or a 30x4.6 mm ID Spherisorb S3 ODS2 C18 were tested as the first (C-1) separation column. A 100x4.6 mm ID analytical column packed with $3 \mu \mathrm{m}$ Chrompack C18 (Varian) was used as C-2.

The photochemical reaction was carried out in a post-column photochemical reactor (Softron GmbH, Gynkotek HPLC, Germering, Germany) fitted with a knitted open tube reactor coil (5mx1.6mm OD and $0.3 \mathrm{~mm}$ ID) PTFE and a $4 \mathrm{~W}$ Xenon lamp. The acquisition and treatment of data were carried out by a personal computer using Millennium32 (Waters) software.

A Model PT 2100 polytron (Kinematica AG, Luzern, Switzerland) was used to homogenize vegetable samples. A Model VV2000 LIF rotary vacuum evaporator (Heidolph) thermostated by water circulation with a $\mathrm{N}-010 \mathrm{KN}-18$ vacuum pump (Telstar) was used to evaporate the extracts.

\subsection{Preparation of standards and spiked samples}

Individual analytical standard stock solutions of pesticides $\left(200 \mathrm{mg} \mathrm{L}^{-1}\right)$ were prepared by exactly weighing and dissolving the corresponding compounds in ACN. They were stable for at 
least 3 months. Calibration standard solutions were freshly prepared in solvent by adding different volumes of the individual stock solutions in ACN:water (50:50, v/v). Matrix-matched standards were prepared in the same way, but using blank extracts of fresh vegetable samples obtained as described in the "Extraction Procedure" section, at the same concentration as the solvent based calibration standards for each commodity. All standard solutions were protected against light and were stored in a refrigerator at $48 \mathrm{C}$.

For recovery determinations, samples (15 g) of finely chopped vegetable were spiked by addition of a standard stock solution $\left(2 \mathrm{mg} \mathrm{L}^{-1}\right)$, at two levels of concentration: 10 and $33.3 \mu \mathrm{g} \mathrm{kg}^{-1}$ (equivalent to 15 and $50 \mu \mathrm{g} \mathrm{L}^{-1}$ in the final extract) for each of the pesticides. Before extraction, the spiked samples were allowed to stand for long enough (about $20 \mathrm{~min}$.) to allow the spiking solution to penetrate the test material.

\subsection{Extraction procedure}

Dichloromethane $(35 \mathrm{~mL})$ was added to $15 \mathrm{~g}$ of a vegetable sample in a container glass and mixed for 2 min with Polytron. Then, $40 \mathrm{~g}$ of sodium sulfate was added and the mixture was homogenized for $1 \mathrm{~min}$. The extract was filtered through a porous plate, and two successive $20 \mathrm{~mL}$ portions of dichloromethane were added for washing the chopped sample. The filtered liquid was collected in a $250 \mathrm{~mL}$ spherical flask and evaporated almost to dryness in a rotating vacuum evaporator with a water-bath at $40 \pm 1^{\circ} \mathrm{C}$ and the remaining solvent was allowed to evaporate under a gentle $\mathrm{N}_{2}$ stream.

The residue obtained from the extract was redissolved in $5 \mathrm{~mL}$ of ACN. Then, $1 \mathrm{~mL}$ of sample extract (equivalent to $3 \mathrm{~g}$ of vegetable sample) was diluted with $1 \mathrm{~mL}$ of water to give a final extract in ACN:water (50:50, v/v) and filtered through a $0.45 \mu \mathrm{m}$ Teflon filter. At the end, $500 \mu \mathrm{L}$ of the final extract was injected into the LC-LC-PIF-FD.

\subsection{LC-LC-PIF-FD analysis}

The mobile phase (M-1) through the first column (C-1) consisted of MeOH:water (70:30, v/v) while a mobile phase (M-2) of $\mathrm{MeOH}$ :water in gradient was used on the second column (C-2) (Table 1). Both mobile phases were adjusted to a flow rate of $0.5 \mathrm{~mL} \mathrm{~min}^{-1}$.

The UV photoreactor was connected on-line after the C-2 column for the PIF derivatization of benzoylureas. Fluorimetric detection was performed at an excitation wavelength ( $\lambda$ ex) of $344 \mathrm{~nm}$ and at an emission wavelength ( $\lambda \mathrm{em})$ of $418 \mathrm{~nm}$ for all pesticides.

The analytical process was as follows: after injection of $500 \mu \mathrm{L}$ of un-cleaned vegetable extract on the $\mathrm{C}-1$ column, a clean-up was performed for $2 \mathrm{~min}$ with $1 \mathrm{~mL}$ of $\mathrm{M}-1$. During this step a large 
amount of the interferences are removed from C- 1 to waste. Just before the elution of the first analyte takes place, $\mathrm{C}-1$ is switched on-line with the second separation column, C-2, for 2.30 min, when the fraction containing the analytes is completely transferred from C-1 to C-2 with M-2. Finally, the switching valve was turned back to the initial position to disconnect C-1 and C-2, so the analytes are separated on C-2 with M-2 while simultaneously interferences are washed from C-1 with M-1 and this column is preconditioned with M-1 prior to the next injection. Benzoylureas were completely separated in C-2 under the established gradient program.

\section{Results and discussion}

\subsection{LC-separation and fluorescence detection after photoderivatization}

With the aim of obtaining information useful in LC with PIF and fluorescence detection, batch studies were carried out in previous work [27]. Thus, we established the excitation and emission spectra for these benzoylureas in different binary aqueous mixtures. The strongest fluorescence signal occurred in aqueous mixtures of ethanol followed by $\mathrm{MeOH}$ and $\mathrm{ACN}$. From this data, we selected an emission wavelength of $418 \mathrm{~nm}$ after excitation at $344 \mathrm{~nm}$ as the better compromise wavelengths for all of them. No significant changes were found in either sensitivity or selectivity of the analytes for $\mathrm{pH}$ values between 3 and 8 and therefore no buffer was used in the mobile phase.

Two parameters, the UV irradiation time and the type of solvent used [28], affect the sensitivity of the method. In order to obtain the maximum response and the best separation, different mobile phases and flow rates (residence time on the photoreactor) were examined using the C-2 column. We selected a flow rate of $0.5 \mathrm{~mL} \mathrm{~min}{ }^{-1}$ for M-2 and a gradient program with MeOH:water (Table 1) as a compromise solution between the residence time in the reactor and the broadening of bands on the chromatogram.

Table 1. Gradient program used as M-2 for the separation of benzoylureas in C-2.

\begin{tabular}{cc}
\hline Time (min) & MeOH:water (v/v) \\
\hline 0 & $70: 30$ \\
5 & $70: 30$ \\
8 & $90: 10$ \\
13 & $90: 10$ \\
15 & $70: 30$ \\
22 & $70: 30$ \\
\hline
\end{tabular}




\subsection{Switching parameters}

The next step involves adjustment of the chromatographic conditions on the first column (C-1). Clean-up and transfer volumes are estimated by directly connecting C-1 to the detector. Therefore, as benzoylureas do not show native fluorescence and in order to avoid the analytes getting through the photoreactor these studies were performed using the UV detector, measuring absorbance at 210 nm.

When analytes and interferents are of the same nature they are difficult to separate in the analytical column (C-2), whose stationary phase is usually $\mathrm{C} 18$. Therefore it seems adequate to use a C-1 sorbent with different retention mechanism as compared to C-2. Thus, RAM columns combine the size exclusion of high molecular components with the retention of target analyte inside the adsorbent $[29,30]$.

However, C18 columns have been widely used as C-1 in LC-LC with good results [31]. Therefore columns of different nature were tested (a 30x4.6 mm ID Spherisorb S3 ODS2 C18 and a 50x4.6 mm ID packed with $5 \mu \mathrm{m}$ Pinkerton ISRP) with the aim of comparing their performance in the clean-up and transfer volume steps.

The composition and flow rate of the mobile phase $\mathrm{M}-1$ through $\mathrm{C}-1$ were adjusted to provide a good separation between analytes and interferents. In this way, different $\mathrm{MeOH}$ :water mixtures were evaluated. An increase in the percentage of water in the mobile phase increases the retention of the interferences and analytes on the C-1 but did not improve the separation between them. Experiments indicated that a mobile phase flow of $0.5 \mathrm{~mL} \mathrm{~min}^{-1}$ with $\mathrm{MeOH}$ :water $(70: 30, \mathrm{v} / \mathrm{v})$ for M-1 during 2 min was a good compromise between clean-up and elution of analytes. Under these conditions, the clean-up volume was $1 \mathrm{~mL}$.

Another crucial feature of LC-LC is the transfer volume in order to obtain optimal selectivity at a minimal transfer volume. As the transfer step is carried out with M-2, it is necessary to optimize the eluotropic strength of this mobile phase in order to reach an adequate compromise between the required separation efficiency on the second column and the desired peak compression (sensitivity of detection) on the first one.

Generally, the eluotropic strength of M-2 is always higher than that of M-1 in order to enhance sensitivity by means of peak compression and to reduce the time of analysis by reducing the transfer step. In addition its composition must be adequate to provide satisfactory separation of analytes on C-2. However, there will probably be a limited choice of M-2 because of the expected poor retention of the analytes of interest. In this way, different percentages of $\mathrm{MeOH}$ :water and flow rates were assayed. In our case, due to the low retention of the benzoylureas in $\mathrm{C}$-1, increasing the 
percentage of $\mathrm{MeOH}$ or the flow rate did not provide any great improvement in peak compression. A mobile phase of $0.5 \mathrm{~mL} \mathrm{~min}{ }^{-1} \mathrm{MeOH}$ :water (70:30, v/v) was chosen. Under these conditions, the transfer step was carried out for 2.3 minutes.

\subsection{Injection volume}

Use of the LC-LC approach provides a significant reduction of the detection limit as the injection of large volume sample (LVI) into the chromatographic system is possible without causing unacceptable band broadening. The injection volume was optimized by connecting $\mathrm{C}-1$ to the detector.

Different loops were tested in order to optimize the signal-to-noise ratio and thus to improve the detection limit. LVI was studied by injecting different volumes containing $10 \mu \mathrm{g}$ of each compound in $\mathrm{ACN}$ :water (50:50 v/v) onto $\mathrm{C}-1$ and using $\mathrm{MeOH}$ :water (70:30, v/v) as mobile phase. The volumes ranged from 200 to $2000 \mu \mathrm{L}$. Volumes higher than $500 \mu \mathrm{L}$ led to a reduction in the signal height of the analytes as well as increases in retention time and band broadening, which will imply poor separation on C-2. A sample volume of $500 \mu \mathrm{L}$ was selected as a compromise between the required sensitivity and speed of analysis.

Even though the two columns perform an adequate clean up step, C18 makes the peak shape wider and more asymmetric than when using the ISRP column; in addition ISRP column allows shorter times of analysis as can be seem in Figure 1.a and Figure 1.b, respectively. As can be seen, a total time of $22 \mathrm{~min}$, including the reconditioning time of the column was enough to determine the five benzoylureas, when using the ISRP column as C-1.

On using a C-1 which provides relatively less retention of the analytes than $\mathrm{C}-2$, some phase focusing of the analytes is obtained when the analytes are transferred from C- 1 to the C- 2 column. This refocusing is beneficial to obtain high efficiency on the second column when large volumes of analytes are introduced into the LC-LC system.

\subsection{Extraction and analysis}

Dichloromethane is reported to be satisfactory extractant for the studied benzoylureas [22,32]. The extraction procedure described in the experimental section was applied to spiked cucumber, green been, tomato, and aubergine samples. The LC-LC-PIF-FD analysis was carried out online by means of $500 \mu \mathrm{L}$ LVI, which provided sufficient sensitivity. Chromatograms without interferences at the retention times corresponding to those of the analytes were found for all vegetables assayed. Figure 2 shows LC-LC-PIF-FD chromatograms of a tomato blank extract and of a tomato extract containing all the analytes at a spiking level of $10 \mu \mathrm{g} \mathrm{kg}^{-1}$ (corresponding to $15 \mu \mathrm{g} \mathrm{L}^{-1}$ in the final 
extract), respectively. Peaks of benzoylureas were well resolved and showed no interferences with the vegetable matrix.
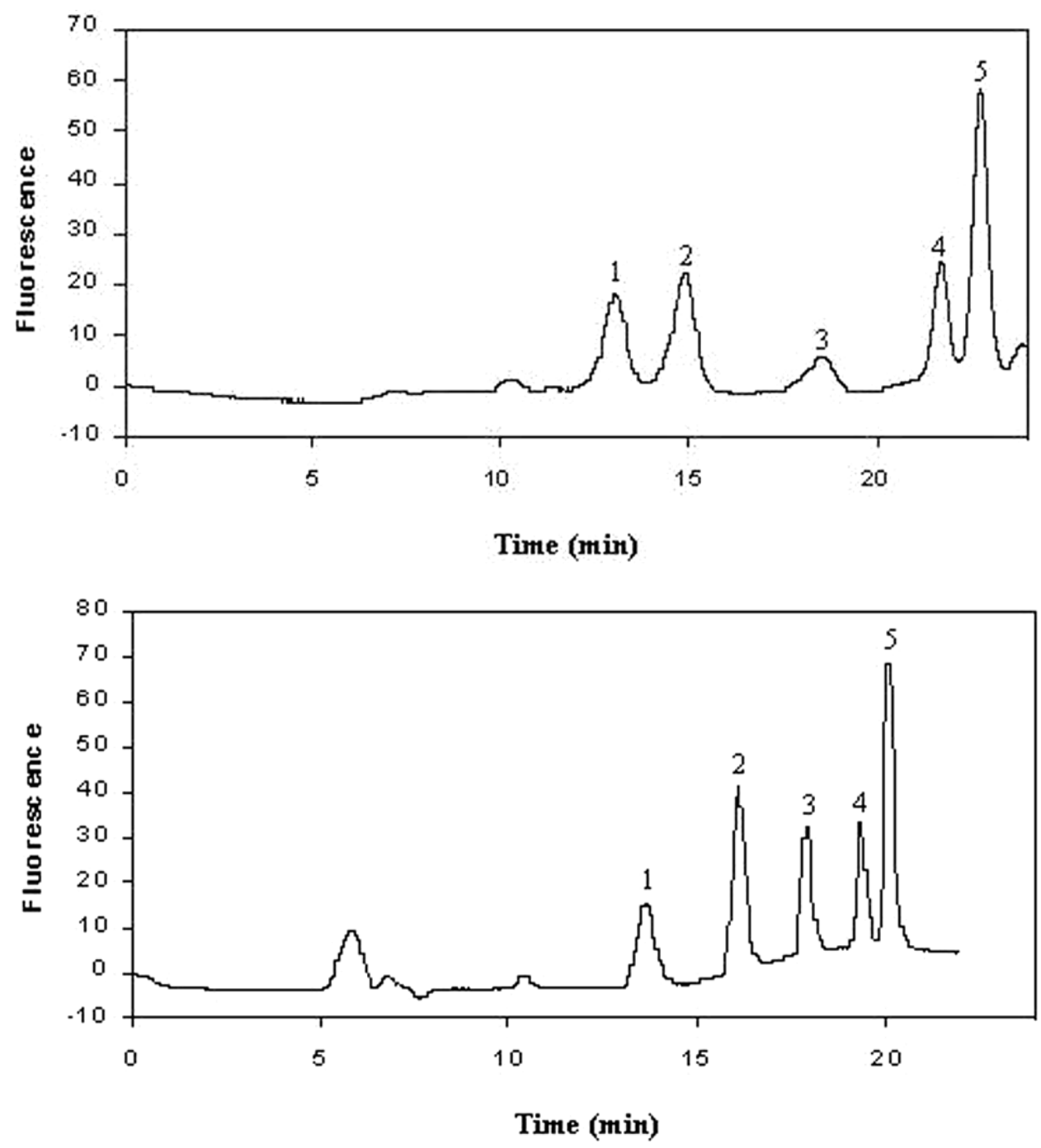

Figure 1. LC-LC-PIF-FD chromatograms obtained from a tomato extract spiked with $50 \mu \mathrm{g} \mathrm{L}^{-1}$ of all analytes with $\mathrm{C}-1$ for: (a) $\mathrm{C} 18$ column and (b) ISRP at a mobile phase flow rate of $0.5 \mathrm{~mL} \mathrm{~min}{ }^{-1}$ with $\mathrm{MeOH}$ :water (70:30, v/v). Peak number: 1, diflubenzuron; 2, triflumuron; 3, hexaflumuron; 4, lufenuron; 5, flufenoxuron. 


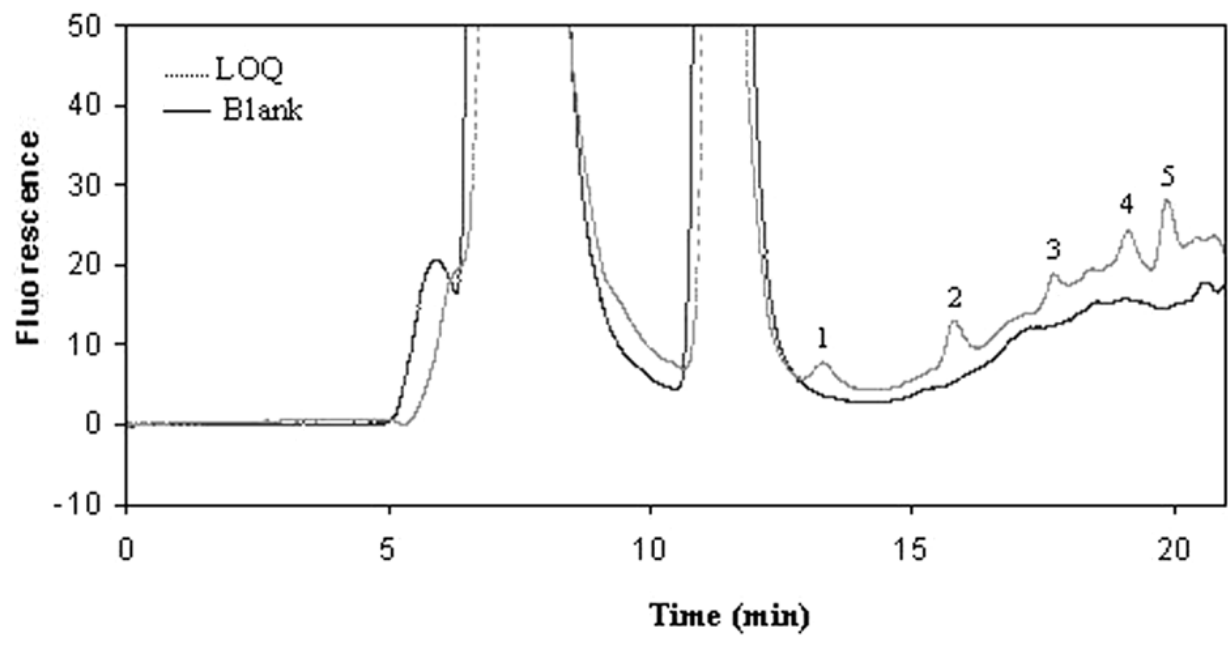

Figure 2. LC-LC-PIF-FD chromatograms of: (a) a tomato blank extract and (b) a tomato sample spiked at $10 \mu \mathrm{g} \mathrm{kg}^{-1}$. Peak number: 1, diflubenzuron; 2, triflumuron; 3, hexaflumuron; 4, lufenuron; 5 , flufenoxuron

\subsection{Validation of the LC-LC-PIF-FD method}

When an analytical method is proposed for the analysis of real samples, it is necessary to proceed to validate it in the target matrices. The LC-LC-PIF-FD method was validated using solvent and extracts obtained from a series of four vegetable samples not containing these pesticides. Analytical figures of merit using both solvent-based and matrix-matched standards are shown in Table 2 and Table 3, respectively.

Table 2. Analytical figures of merit for the determination of benzoylureas in solvent.

\begin{tabular}{lcccccc}
\hline Pesticide & $\begin{array}{c}\text { Linear range } \\
{\left[\mu \mathrm{g} \mathrm{L}^{-1}\right]}\end{array}$ & $\mathrm{R}^{2}$ & $\mathrm{RSD} *[\%]$ & $\begin{array}{c}\mathrm{LOD}^{\mathrm{a})} \\
{\left[\mu \mathrm{g} \mathrm{L}^{-1}\right]}\end{array}$ & $\begin{array}{c}\mathrm{LOQ}^{\mathrm{a})} \\
{\left[\mu \mathrm{g} \mathrm{L}^{-1}\right]}\end{array}$ & $\begin{array}{c}\mathrm{LOQ}^{\mathrm{b})} \\
{\left[\mu \mathrm{g} \mathrm{L}^{-1}\right]}\end{array}$ \\
\hline DFB & $4-1500$ & 0.9987 & 3.4 & 0.28 & 1.07 & 4.0 \\
TFM & $3-1500$ & 0.9991 & 4.2 & 0.22 & 0.86 & 3.0 \\
HFM & $3-1000$ & 0.9992 & 3.7 & 0.23 & 1.05 & 3.0 \\
LF & $3-1000$ & 0.9998 & 4.3 & 0.24 & 0.99 & 3.0 \\
FF & $2-1800$ & 0.9997 & 3.2 & 0.12 & 0.48 & 2.0 \\
\hline
\end{tabular}

* 6 injections of $10 \mu \mathrm{g} \mathrm{L} \mathrm{L}^{-1}$.

a) Based on the values of the blank $(n=10)$ at the RT of the analytes.

b) Based on the lowest concentration where the RSD (\%) is estimated to be less than $10 \%$. 
Table 3. Analytical figures of merit for the determination of benzoylureas in vegetables.

\begin{tabular}{|c|c|c|c|c|c|c|c|}
\hline Pesticide & Matrix & $\begin{array}{l}\text { Linear range } \\
\qquad \mu \mathrm{g} \mathrm{L}^{-1]}\end{array}$ & $\mathrm{R}^{2}$ & RSD* [\%] & $\begin{array}{c}\mathrm{LOD}^{\mathrm{a})} \\
{\left[\mu \mathrm{g} \mathrm{L}^{-1}\right]}\end{array}$ & $\begin{array}{c}\mathrm{LOQ}^{\mathrm{a})} \\
{\left[\mu \mathrm{L} \mathrm{L}^{-1}\right]}\end{array}$ & $\begin{array}{c}\mathrm{LOQ}^{\mathrm{b})} \\
{\left[\mu \mathrm{g} \mathrm{L}^{-1}\right]}\end{array}$ \\
\hline \multirow[t]{4}{*}{ DFB } & aubergine & $10-1500$ & 0.9971 & 4.1 & 0.33 & 1.31 & 10 \\
\hline & cucumber & $7-1500$ & 0.9999 & 5.7 & 0.26 & 1.14 & 7 \\
\hline & green bean & $5-1500$ & 0.9999 & 6.4 & 0.64 & 2.17 & 5 \\
\hline & tomato & $8-1500$ & 0.9999 & 3.7 & 0.48 & 1.87 & 8 \\
\hline \multirow[t]{4}{*}{ TFM } & aubergine & $6-1500$ & 0.9999 & 4.5 & 0.31 & 1.09 & 6 \\
\hline & cucumber & $5-1500$ & 0.9984 & 6.2 & 0.24 & 1.01 & 5 \\
\hline & green bean & $6-1500$ & 0.9996 & 8.2 & 0.98 & 3.66 & 6 \\
\hline & tomato & $6-1500$ & 0.9996 & 2.5 & 0.47 & 1.64 & 6 \\
\hline \multirow[t]{4}{*}{ HFM } & aubergine & $10-1000$ & 0.9996 & 2.9 & 0.48 & 1.74 & 10 \\
\hline & cucumber & $4-1000$ & 0.9981 & 2.4 & 0.21 & 0.89 & 4 \\
\hline & green bean & $9-1000$ & 0.9998 & 3.6 & 0.44 & 1.60 & 9 \\
\hline & tomato & $9-1000$ & 0.9996 & 2.9 & 0.52 & 1.82 & 9 \\
\hline \multirow[t]{4}{*}{$\overline{L F}$} & aubergine & $4-1000$ & 0.9999 & 4.6 & 0.74 & 2.60 & 4 \\
\hline & cucumber & $5-1000$ & 0.9999 & 3.9 & 0.36 & 1.88 & 5 \\
\hline & green bean & $5-1000$ & 0.9997 & 5.2 & 0.83 & 3.99 & 5 \\
\hline & tomato & $9-1000$ & 0.9993 & 5.7 & 0.61 & 2.17 & 9 \\
\hline \multirow[t]{4}{*}{ FF } & aubergine & $7-1800$ & 0.9999 & 2.0 & 0.31 & 1.07 & 7 \\
\hline & cucumber & $7-1800$ & 0.9931 & 3.6 & 0.22 & 0.75 & 7 \\
\hline & green bean & $9-1800$ & 0.9969 & 5.2 & 0.73 & 2.48 & 9 \\
\hline & tomato & $5-1800$ & 0.9994 & 2.8 & 0.82 & 2.37 & 5 \\
\hline
\end{tabular}

Limits of detection (LOD) and limits of quantification (LOQ) were calculated statistically [33] as 3.84- and 10-fold, respectively, the standard deviation of the signals corresponding to 10 blanks of solvent and of vegetable samples, divided by the slope of the calibration curve. The LOQs were also calculated according to the EURACHEM Guidance document [34], as the lowest concentration for which the relative standard deviation (RSD) is equal to or less than a fixed percentage (10\% in our case). The LOQ values were higher when the second criterion was used, in agreement with the result found by other authors [35]. We consider that the latter approach estimates more realistic values. These LOQs obtained for each pesticide using solvent-based and matrix matched calibration graphs were both lower than their respective MRL, in compliance with the Guidance Document on Residue Analytical Method [36].

In all cases, these LODs and LOQs were significantly lower than those reported by other techniques without column switching mode, such as GC-ECD [37], LC-UV [18,20,21] or PIF $[38,39]$ and are in the same order as those obtained by LC-PIF-FD [22] and LC-MS [23-25], using a SPE step in all cases.

In general, correlation coefficients higher than 0.99 were obtained for all pesticides in all cases, this being the lower limit of the linear range of the LOQ calculated according to the EURACHEM 
Guidance document; the upper limit is the concentration for which the signal deviates from linearity by $3-5 \%$ [40].

When calibration graphs obtained using solvent-based and matrix-matched standards were compared, an enhancement or suppression effect on the analytical signal, which was due to the matrix, was observed for some compounds in the vegetable matrices. With the aim of checking the presence of matrix effect, the slopes of calibration graphs obtained in both ways were compared for each pesticide and matrix by means of a t-test [40]. The results of the t-test showed significant differences between the slopes of the two calibration curves for DFB and TFM in all vegetables, except in green beans, as well as for FF in this matrix.

Precision within-day was tested for the LC-LC-PIF method, also by using solvent and matrixmatched standards. The RSD (\%) values $(\mathrm{n}=6)$, obtained by injecting $10 \mu \mathrm{g} \mathrm{L}^{-1}$ of each pesticide for solvent standard and $25 \mu \mathrm{g} \mathrm{L}^{-1}$ of each pesticide for matrix standard, were lower than 4.5 and $8.5 \%$, respectively.

In order to establish the accuracy and precision of the total method, 6 replicates of vegetable samples were spiked with 10.0 and $33.3 \mu \mathrm{g} \mathrm{kg}^{-1}$ of each benzoylurea, extracted, and analyzed by using the described method. The mean recovery percentages and the standard associated deviations, using solvent-based and matrix matched standards for quantification, are shown in Table 4. In general, it can be observed that recoveries obtained using both calibration curves were satisfactory for all the pesticides (119.2-77.6\%), which are in the range expected for residue analysis. Nevertheless, for those cases in which the existence of matrix effect was demonstrated by comparing the slopes of calibration curves, the results are better when the quantification is performed using matrix-matched calibration graphs (112.4-77.6\%) as may be expected. Therefore, in those cases the quantification should be carried out using the calibration curves prepared with standards on blank vegetable extracts. Results of accuracy and precision are in agreement with the criteria of European Guidelines [36].

During this study no significant decrease of the signals or shifts in retention times of analytes were observed for the column-switching LC-LC-PIF-FD procedure even five months later (at about 15 samples at day), emphasizing the robustness of the methodology.

\subsection{Analysis of real samples}

The proposed method was applied for analyzing tomato samples in the "Residue Analysis Laboratory CUAM" in Almer_a, accredited according to EN 17025. Some of the benzoylurea insecticides were present in about $2 \%$ of the analyzed samples, at levels lower than the MLRs [41]. 
Table 4. Recovery percentages and RSD (\%) for samples spiked at two concentration levels (10.0 and 33.3 $\mu \mathrm{g} \mathrm{kg}^{-1}$ ) carrying out the quantification with calibration curves built with standard solutions prepared in solvent and in the corresponding vegetable matrix extract.

\begin{tabular}{|c|c|c|c|c|c|c|c|c|c|}
\hline \multirow[t]{3}{*}{ Pesticide } & \multirow{3}{*}{$\begin{array}{l}\text { Conc. } \\
{\left[\mu \mathrm{g} \mathrm{L}^{-1}\right]}\end{array}$} & \multicolumn{8}{|c|}{ Recovery [\%] } \\
\hline & & \multicolumn{2}{|c|}{ Aubergine } & \multicolumn{2}{|c|}{ Cucumber } & \multicolumn{2}{|c|}{ Green Bean } & \multicolumn{2}{|c|}{ Tomato } \\
\hline & & Solvent & Matrix & Solvent & Matrix & Solvent & Matrix & Solvent & Matrix \\
\hline \multirow[t]{2}{*}{ DFB } & 10.0 & $116.1(4.1)$ & $108.9(5.0)$ & $89.0(6.4)$ & $98.8(7.4)$ & $78.0(4.0)$ & $77.6(6.4)$ & $93.1(2.0)$ & $110.4(2.4)$ \\
\hline & 33.3 & $73.1(2.6)$ & $95.7(3.1)$ & $83.0(3.9)$ & $94.5(3.9)$ & $94.0(1.7)$ & $93.2(2.8)$ & $83.1(3.3)$ & 97.7 (1.6) \\
\hline \multirow[t]{2}{*}{ TFM } & 10.0 & $80.9(3.4)$ & $97.3(3.8)$ & $88.3(6.9)$ & $89.4(7.5)$ & $100.1(10.0)$ & $95.0(10.0)$ & $99.6(1.7)$ & $111.6(1.8)$ \\
\hline & 33.3 & $92.8(4.0)$ & $104.0(4.4)$ & $87.3(6.0)$ & $88.0(5.8)$ & $92.3(6.4)$ & $86.2(6.4)$ & $85.3(0.9)$ & $86.4(1.0)$ \\
\hline \multirow[t]{2}{*}{ HFM } & 10.0 & $85.1(2.9)$ & $87.7(3.4)$ & $106.8(2.5)$ & $109.8(2.6)$ & $102.0(2.5)$ & $109.8(2.7)$ & $109.7(2.6)$ & $112.4(2.7)$ \\
\hline & 33.3 & $80.0(1.9)$ & $82.1(2.0)$ & $95.6(3.7)$ & $96.9(1.6)$ & $92.6(1.2)$ & $96.2(1.4)$ & $93.2(4.4)$ & $94.8(1.4)$ \\
\hline \multirow[t]{2}{*}{ LF } & 10.0 & $105.1(4.2)$ & $102.2(4.5)$ & $111.0(5.4)$ & $109.9(5.3)$ & $104.2(6.1)$ & $104.9(6.7)$ & $109.2(5.5)$ & $103.1(5.0)$ \\
\hline & 33.3 & $92.7(2.8)$ & $90.1(3.0)$ & $108.3(1.4)$ & $106.4(1.9)$ & $105.2(2.7)$ & $98.4(3.0)$ & $95.3(4.6)$ & $84.5(3.8)$ \\
\hline \multirow[t]{2}{*}{ FF } & 10.0 & $90.6(4.9)$ & $95.5(5.3)$ & $90.2(3.7)$ & $92.5(3.9)$ & $85.3(9.3)$ & $99.3(9.2)$ & $119.2(3.4)$ & $80.4(3.1)$ \\
\hline & 33.3 & $95.0(1.9)$ & $99.5(2.0)$ & $90.4(7.4)$ & $92.8(3.5)$ & $80.4(3.8)$ & $94.4(3.7)$ & $108.6(6.3)$ & $95.1(2.9)$ \\
\hline
\end{tabular}

RSD (\%) in parentheses $(\mathrm{n}=6)$.

\section{Conclusion}

LC-LC has been applied for determination of pesticides in dichloromethane extract of vegetable samples without clean-up step. The main advantage of LC-LC is the use of the separation power of the first column (C-1) to perform an efficient clean-up. It effectively eliminates early eluting interferences, allowing reliable quantification of analytes which appear in the first part of the chromatograms. The improvement in sensitivity with PIF methodology linked with the LVI allows, in a cost-effective way, the determination of benzoylureas in vegetables samples at levels down to established MRLs. Thus, a very rapid, sensitive, selective, and robust method useful for screening purposes in monitoring programs was developed.

\section{Acknowledgment}

The authors are grateful to the INIA (Project CAL-00-063) and FIAPA for financial support received in the realization of this work.

\section{References}

[1] D. Barceló, Sample Handling and Trace Analysis Pollutants Techniques, Applications and Quality Assurance, Elsevier Science, 2000, Chap. 8. 
[2] A. Di Muccio, S. Girolimetti, D.A. Barbini, P. Pelosi, T. Generali, L. Vergori, G. De Merulis, A. Leonelli, P. Stefanelli, J. Chromatogr. A 1999, 833, 61.

[3] V. Coquart, M.-C. Hennion, J. Chromatogr. A 1991, 585, 67.

[4] V. Coquart, M.-C. Hennion, Sci. Total Environm. 1993, 132, 349.

[5] V. Pichon, L. Chen, M.-C. Hennion, Anal. Chim. Acta 1995, 311, 429.

[6] E.A. Hogendoorn, P. van Zoonen, A. Polettini, G.M. Bouland, M. Montagna, Anal. Chem. 1998, 70, 1362.

[7] P. Parrilla-Vázquez, J. Martínez-Fernández, M.D. Gil-García, J. Liquid Chromatogr. Rel. Tech. $2002,25,3045$.

[8] E.A. Hogendoorn, P. van Zoonen, P. Med. Fac. Landbouww. Rijksuniv. Gent 1991, 56/3a, 933.

[9] P. Parrilla, P. Kaim, E.A. Hogendoorn, R.A. Baumann, Fresenius J. Anal. Chem. 1999, 363, 77.

[10] E.A. Hogendoorn, K. Westhuis, E. Dijkman, H.A.G. Heusinkveld, A.C. den Boer, E.A.I.M. Evers, R.A. Baumann, J. Chromatogr. A 1999, 858, 45.

[11] P. Parrilla-Vázquez, J.L. Martínez-Vidal, J. Martínez-Fernández, Analyst 2000, 125, 1549.

[12] E.A. Hogendoorn, F.M. Ossendrijver, E. Dijkman, R.A. Baumann, J. Chromatogr. A 1999, $833,67$.

[13] E. Van der Heeft, E. Dijkman, R.A. Baumann, E.A. Hogendoorn, J. Chromatogr. A 2000, 879, 39.

[14] E. Dijkman, D. Mooibroek, R. Hoogerbrugge, E.A. Hogendoorn, J.-V. Sancho, O. Pozo, F. Hernández, J. Chromatogr. A 2001, 926, 113.

[15] British Crop Protection Council and The Royal Society of Chemistry, The Pesticide Manual, 10th Ed., British Crop Protection Council and The Royal Society of Chemistry, London 1994, UK.

[16] N.G. Tsiropoulos, P.G. Aplada-Sarlis, G.E. Miliadis, J. AOAC Int. 1999, Vol. 82, No. 1.

[17] C. Bicchi, C. Balbo, A. Binello, A. D’Amato, J. High Resol. Chromatogr. 1996, 19, 105.

[18] M. Gamon, R. Pelegri, I. Peris, J.G. de la Cuadra, R. Coscolla, J. AOAC Int. 1998, 81, 1037.

[19] A. Balinova, J. Chromatogr. A 1998, 823, 11.

[20] C. Bicchi, C. Balbo, A. D’Amato, O. Panero, Chromatographia 1996, 43, 439.

[21] C. Bicchi, C. Balbo, A. Binello, A. D’Amato, J. High Resol. Chromatogr. 1996, 19, 105.

[22] M. Martínez-Galera, T. López-López, M.D. Gil-García, J.L. Martínez-Vidal, P. ParrillaVázquez, J. Chromatogr. A 2001, 918, 79.

[23] K.A. Barnes, R.J. Fussell, J.R. Startin, S.A. Thorpe, S.L. Reynold, Rapid Commun. Mass Spectrom. 1995, 9, 1441.

[24] K.A. Barnes, R.J. Fussell, J.R. Startin, M.K. Pegg, S.A. Thorpe, S.L. Reynolds, Rapid Commun. Mass Spectrom. 1997, 11, 117. 
[25] A. Garrido-Frenich, M.D. Gil-García, F.J. Arrebola, J.L. Martínez-Vidal, M. Martínez-Galera, T. López-López, Chromatographia 2000, 52, 569.

[26] A. Coly, J.J. Aaron, Talanta 1998, 46, 815.

[27] M.D. Gil-García, M. Martínez-Galera, T. López-López, J.L. Martínez-Vidal, M.C. Mahedero, F. Salinas, Talanta 2001, 53, 915.

[28] A. Coly, J.J. Aaron, Analyst 1994, 119, 1205.

[29] S. Vielhauer, A. Rudolphi, K.S. Boos, D. Seidel, J. Chromatogr. B 1995, 666, 315.

[30] K.S. Boos, A. Rudolphi, LC-GC Int. 1997, 15, 602.

[31] P. Parrilla Vázquez, J.L. Martínez Vidal, J. Martínez Fernández, J. Chromatogr. B 2000, 738, 387.

[32] J.L. Tadeo, C. Sanchez-Brunete, R.A. Pérez, M.D. Fernandez, J. Chromatogr. A 2000, 882, 175.

[33] L.A. Currie, Anal. Chim. Acta 1999, 391, 105.

[34] L. Huber, LC-GC Int. 1998, 11, 96.

[35] M.C. Pablos-Espada, F.J. Arrebola-Liebanas, A. Garrido-Frenich, J.L. Martínez-Vidal, Int. J. Environ. Anal. Chem. 1999, 75, 165.

[36] European Commission, SANCO/825/00 Rev.6, 20/06/00.

[37] J.K. Mensah, E. Lundanes, T. Greibrokk, B. Holen, J. Chromatogr. A 1997, 765, 85.

[38] J.J. Aaron, A. Coly, Analyst 1996 121, 1545.

[39] A. Coly, J.J. Aaron, Anal. Chim. Acta 1998, 360, 129.

[40] D.L. Massart, B.G.M. Vandeginste, L.M.C. Buydens, S. De Jong, P.J. Lewi, J. SmeyersVerbeke, Handbook of Chemometrics and Qualimetrics: Part. 2, Elsevier Science, Amsterdam (The Netherlands) 1997.

[41] Legislación Internacional de residuos de plaguicidas en productos vegetales, Secretaria General de Comercio Exterior de España, NIPO: 101-99-108-9, 1999. 